\title{
openheart The impact of passive and active smoking on inflammation, lipid profile and the risk of myocardial infarction
}

\author{
Ritienne Attard, ${ }^{1}$ Philip Dingli, ${ }^{1}$ Carine J M Doggen, ${ }^{2}$ Karen Cassar, ${ }^{3}$ \\ Rosienne Farrugia, ${ }^{1}$ Stephanie Bezzina Wettinger ${ }^{1}$
}

\begin{abstract}
- Additional material is published online only. To view, please visit the journal online (http://dx.doi.org/10.1136/ openhrt-2017-000620).
\end{abstract}

To cite: Attard R, Dingli P, Doggen CJM, et al. The impact of passive and active smoking on inflammation, lipid profile and the risk of myocardial infarction. Open Heart 2017;4:e000620. doi:10.1136/ openhrt-2017-000620

Received 23 February 2017 Revised 24 May 2017 Accepted 13 June 2017

\section{CrossMark}

${ }^{1}$ Department of Applied Biomedical Science, Faculty of Health Sciences, University of Malta, Msida, Malta

${ }^{2}$ Health Technology and Services Research, MIRA, University of Twente, Enschede, The Netherlands

${ }^{3}$ Faculty of Medicine and Surgery, University of Malta, Msida, Malta

Correspondence to Dr Stephanie Bezzina Wettinger stephanie.bezzina-wettinger@ um.edu.mt

\section{ABSTRACT}

Objective To investigate the effect of passive smoking, active smoking and smoking cessation on inflammation, lipid profile and the risk of myocardial infarction (MI). Methods A total of 423 cases with a first Ml and 465 population controls from the Maltese Acute Myocardial Infarction (MAMI) Study were analysed. Data were collected through an interviewer-led questionnaire, and morning fasting blood samples were obtained. ORs adjusted for the conventional risk factors of $\mathrm{Ml}$ (aORs) were calculated as an estimate of the relative risk of Ml. The influence of smoking on biochemical parameters was determined among controls.

Results Current smokers had a 2.7 -fold $(95 \% \mathrm{Cl} 1.7$ to 4.2 ) and ex-smokers a 1.6 -fold $(95 \% \mathrm{Cl} 1.0$ to 2.4$)$ increased risk of Ml. Risk increased with increasing pack-years and was accompanied by an increase in highsensitivity $C$ reactive protein levels and an abnormal lipid profile. Smoking cessation was associated with lower triglyceride levels. Exposure to passive smoking increased the risk of $\mathrm{Ml}$ (aOR $3.2(95 \% \mathrm{Cl} 1.7$ to 6.3$))$, with the OR being higher for individuals exposed to passive smoking in a home rather than in a public setting (aOR 2.0 (95\% Cl 0.7 to 5.6) vs aOR 1.2 ( $95 \% \mathrm{Cl} 0.7$ to 2.0)). Passive smoke exposure was associated with higher levels of total cholesterol, triglycerides and total cholesterol:high-density lipoprotein cholesterol ratio compared with individuals not exposed to passive smoking.

Conclusions Both active and passive smoking are strong risk factors for $\mathrm{Ml}$. This risk increased with increasing pack-years and decreased with smoking cessation. Such effects may be partly mediated through the influence of smoking on inflammation and lipid metabolism.

\section{INTRODUCTION}

Smoking, a known risk factor for myocardial infarction (MI), ${ }^{1}$ influences various mechanisms, which may accelerate atherogenesis. Active smoking has been associated with endothelial dysfunction, ${ }^{2}$ an atherogenic lipid profile including lower levels of high-density lipoprotein (HDL) cholesterol $^{3}$ and with adverse effects on blood coagulability, including increased fibrinogen levels and platelet aggregation. ${ }^{45}$ Less literature is found on the effects of exposure to passive smoking on the risk of MI. Few of these

\section{KEY MESSAGES}

What is already known about this subject?

- The deleterious effect of active smoking is well documented, however, limited and conflicting literature is found regarding the effect of passive smoking both on the risk of $\mathrm{Ml}$ and on the mechanism through which it conveys this effect.

What does this study add?

- This study confirms the deleterious effect of active smoking on the risk of myocardial infarction (MI) along with its effect on inflammation and lipid profile. We also report changes in the lipid profile with years from smoking cessation. Passive smoking was identified as a strong risk factor of MI, with individuals exposed to passive smoking in a home setting being more at risk than those exposed in a public setting. At least part of the increased risk of $\mathrm{Ml}$ associated with passive smoke exposure may be explained by its adverse effect on the lipid profile.

How might this impact on clinical practice?

- Programmes to increase awareness on the risk of Ml posed by passive smoking should be set up. Laws banning smoking in public, including workplaces, should be established in countries where smoking is still allowed in public spaces and enforced in countries where legislation is already in place. Smoking cessation should be encouraged, as at least some of the pathological effects of smoking are reversible.

studies differentiated between exposure at home and in public spaces while taking into account duration of exposure and the effect of potential confounding factors. ${ }^{6-8}$ In addition, limited and conflicting literature is available on the mechanisms that lead to the benefits of smoking cessation on the risk of MI and the increased risk associated with passive smoking. ${ }^{9} 10$

The Maltese Acute Myocardial Infarction (MAMI) Study is a case-control study on the Maltese population, which includes population controls. The influence of active 
smoking, passive smoking and smoking cessation on the risk of MI was investigated as part of this study, together with the effect on inflammation and lipid profile in control subjects.

\section{METHODS}

\section{Study design}

MI was defined according to the guidelines issued by the Joint European Society of Cardiology/American College of Cardiology committee. ${ }^{11}$ Research subjects consisted of 423 consecutive patients admitted with a first MI to Mater Dei Hospital or Gozo General Hospital, Malta, between June 2011 and April 2013 and 465 population controls, all of third-generation Maltese descent. The maximum age of cases was 70 years for men and 75 years for women. Cases were seen twice during the study, once at the time of hospital admission and at least 6 months later at a follow-up visit. Population controls were recruited from the general population through a random list of addresses generated by the National Statistics office. A postal invitation was sent followed by a telephone invitation. Controls with a history of MI, percutaneous coronary intervention or coronary bypass surgery or ECG evidence of a previous or silent MI or of left bundle branch block were excluded from the study. The population control group was frequency matched to cases on sex and 10-year age groups.

\section{Data collection}

Data on conventional risk factors for MI, including age, sex, smoking (both active and passive), alcohol consumption, diabetes mellitus, hypertension, hypercholesterolaemia and other potential risk factors were collected through several sources. These included an extensive interviewer-led questionnaire, physical measurements, including weight, height and waist and hip circumference and morning fasting blood samples on which various biochemical tests were performed. Questionnaire data on 29 cases was not available. Body mass index (BMI) $\left(\mathrm{kg} / \mathrm{m}^{2}\right)$ was calculated. ${ }^{12}$ Current active smokers were those individuals who reported to smoke or use tobacco-containing products. Ex-smokers were those who reported past smoking while non-smokers were individuals who did not report to smoke ever. Both current and past smokers were asked to indicate the average number of cigarettes smoked per day, the age at which they started smoking and in case of ex-smokers the age at which they stopped smoking. Pack-years were calculated by multiplying the number of cigarettes smoked per day by the duration of smoking. Years from smoking cessation were calculated by subtracting the age of quitting smoking from the age at which they started smoking. Individuals exposed to passive smoking were those who reported to currently live with an active smoker/s who smoke/s indoors near them and/or to be exposed to passive smoking in enclosed public spaces including at work.

\section{Blood processing and biochemical tests}

Lipid profile, haemoglobin A1c (HbA1c) and high-sensitivity $\mathrm{C}$ reactive protein (hs-CRP) testing were performed on morning fasting blood samples. Research subjects were instructed to abstain from smoking for at least 12 hours before blood collection to minimise the acute effect of smoking on blood parameters. HbAlc levels were measured on EDTA whole blood using the Bio-Rad Variant II analyser (Bio-Rad Laboratories GmbH, Germany). The lipid profile tests (total cholesterol, HDL cholesterol, low-density lipoprotein (LDL) cholesterol, triglyceride) were assayed in serum samples on the Roche/Hitachi cobas c311 system (Roche Diagnostics GmbH, Germany). LDL cholesterol was calculated using the Friedewald calculation except when triglyceride levels exceeded $4.52 \mathrm{mmol} / \mathrm{L}$, where the direct LDL cholesterol was assayed. Measurements of serum hs-CRP were determined on the Immulite 2000 immunoassay system (Siemens, USA).

\section{Statistical analysis}

The differences in median levels of biochemical parameters between active smokers, passive smokers and non-smokers were assessed in control subjects using the Mann-Whitney test. A p value of less than 0.05 was arbitrarily chosen to indicate significance. Results for these comparisons are for men only since on stratification the number of women in certain categories was small. Ex-smokers who had abstained from smoking for less than 1year were excluded from the analysis of years from smoking cessation. The analysis of passive smoking was restricted to ex-smokers and non-smokers to eliminate confounding by active smoking. The relative risk of MI was calculated using ORs. ORs were adjusted for age (age OR) and for age, sex, regular alcohol consumption, reported hypertension, hypercholesterolaemia, diabetes and BMI (continuous) (aOR). Diabetes and hypercholesterolaemia used for adjustment of these ORs were defined using both the self-reported data from the questionnaire and measurements of HbAlc and total cholesterol, respectively. Individuals with diabetes were defined as having undiagnosed diabetes if they did not report to have diabetes but had elevated HbA1c levels $(\geq 6.5 \%)$. Those that reported to have diabetes were divided into uncontrolled diabetics if they had elevated HbAlc levels $(\geq 6.5 \%)$ and controlled diabetics if they had normal HbA1c levels $(<6.5 \%)$. Individuals who did not report having diabetes and had normal HbAlc levels $(<6.5 \%)$ were defined as non-diabetics. Undiagnosed hypercholesterolaemia was deemed present in individuals who did not report suffering from hypercholesterolaemia but had high total cholesterol levels $(\geq 5.0 \mathrm{mmol} / \mathrm{L})$. Individuals with self-reported hypercholesterolaemia were either uncontrolled if their total cholesterol levels were $\geq 5.0 \mathrm{mmol} / \mathrm{L}$ or controlled if their total cholesterol levels were $<5.0 \mathrm{mmol} / \mathrm{L}$. Those who did not report to have hypercholesterolaemia and had total cholesterol levels $<5.0 \mathrm{mmol} / \mathrm{L}$ were defined as non-hypercholesterolaemics. The 95\% CI was calculated from the logistic regression model. All statistical analyses were performed using SPSS V.21. 


\begin{tabular}{|c|c|c|}
\hline & $\begin{array}{l}\text { Cases with } \\
M^{*} \mathrm{n}=394\end{array}$ & Controls $n=465$ \\
\hline Men (\%) & $316(80.2)$ & $327(70.3)$ \\
\hline Age years, mean (range) & $59(30-75)$ & $55(20-77)$ \\
\hline Smokers, N (\%) & $146(37.1)$ & $105(22.6)$ \\
\hline Ex-smokers, N (\%) & $145(36.8)$ & $161(34.6)$ \\
\hline Regular alcohol drinkers† (\%) & $232(58.9)$ & $311(66.9)$ \\
\hline Reported diabetes (\%) & $110(28.2)$ & $53(11.9)$ \\
\hline Reported hypertension (\%) & $184(47.2)$ & $160(35.6)$ \\
\hline $\begin{array}{l}\text { Reported hypercholesterolaemia } \\
(\%)\end{array}$ & $179(47.0)$ & $160(36.9)$ \\
\hline $\begin{array}{l}\left.\text { Overweight (BMl } 25-30 \mathrm{~kg} / \mathrm{m}^{2}\right) \ddagger \\
\text { (\%) }\end{array}$ & $136(41.7)$ & $197(42.6)$ \\
\hline Obese $\left(\mathrm{BMl}>30 \mathrm{~kg} / \mathrm{m}^{2}\right) \ddagger(\%)$ & $149(45.7)$ & $173(37.4)$ \\
\hline
\end{tabular}

${ }^{*} A$ total of 423 cases gave consent to participate in the study, however, 29 cases did not complete their admission questionnaire so questionnaire data about them is missing.

†Regular alcohol drinkers were defined as research subjects who consumed at least one unit of alcoholic beverage, including beer, wine and spirits, per week in a year. $\ddagger \mathrm{BMI}$ cut-offs were as defined by WHO.

BMI, body mass index; MAMI, Maltese Acute Myocardial Infarction; MI, myocardial infarction.

\section{Ethical considerations}

This study was approved by the research ethics committee of the University of Malta (reference number MD $32 / 2010$ ). Written informed consent was obtained from all individual participants included in the study.

\section{Role of the funding source}

The funding sources played no role in the study design, recruitment of research subjects, analysis and interpretation of the data or in the writing and submission of this paper for publication.

\section{RESULTS}

Characteristics of the MAMI Study cases and population controls are presented in table 1. Cardiovascular risk factors were more prevalent in cases with MI compared with controls.

\section{Risk of MI associated with active and passive smoking}

Active smoking was a risk factor for MI, with current smokers having a 2.7 -fold (95\% CI 1.7 to 4.2 ) increased risk of MI compared with non-smokers. This risk decreased to 1.6-fold (95\% CI 1.0 to 2.4) among ex-smokers (aORs, table 2A). The risk of MI due to active smoking was dependent on the years of smoking and the number of cigarettes smoked. While less than 10 pack-years were not associated with a risk of MI, a higher number of packyears increased this risk, reaching a 6.9 -fold $(95 \%$ CI 3.7 to 12.8) increased risk for smokers with more than 30 pack-years (table 2B).

Passive smoking, reported in $69.2 \%$ of non-smoker and ex-smoker population controls, also increased the risk of MI. Ex-smokers and non-smokers exposed to passive smoking both at home and in public had a 3.2-fold (95\% CI 1.7 to 6.3) increased risk of MI (table 3A). Exposure to passive smoking solely in a home setting gave a higher OR (aOR 2.0 (95\% CI 0.7 to 5.6)) than exposure to passive smoking solely in a public setting (aOR 1.2 (95\% CI 0.7 to 2.0), such as at work, in restaurants and bars (table 3A). These aORs were similar even after excluding ex-smokers who had abstained from smoking for less than 15 years (see online supplementary table $\mathrm{S} 1)$. The lower aOR observed for passive smoke exposure in a public setting was not due to the modifying effect of alcohol consumption which often accompanies passive smoking in public since the aOR for public passive smoking among regular alcohol drinkers and that among non-regular alcohol drinkers are both low (aOR 0.7 (95\% CI 0.4 to 1.4 ) and 0.9 (95\% CI 0.4 to 1.8 ),

Table 2 Risk of Ml in relation to (A) smoking and (B) pack-years

\section{(A) Smoking status}

\begin{tabular}{|c|c|c|c|c|}
\hline & Cases $(n=394)$ & Controls ( $n=465)$ & Age OR $(95 \% \mathrm{Cl})$ & aOR $(95 \% \mathrm{Cl})$ \\
\hline Current smokers & $146(37.1)$ & $105(22.6)$ & 3.1 (2.2 to 4.5$)$ & 2.7 (1.7 to 4.2$)$ \\
\hline Ex-smokers & $145(36.8)$ & $161(34.6)$ & 1.7 (1.2 to 2.4$)$ & $1.6(1.0$ to 2.4$)$ \\
\hline Non-smokers & $103(26.1)$ & $199(42.8)$ & 1.0 & 1.0 \\
\hline \multicolumn{5}{|c|}{ (B) Pack-years* (analysis among current smokers only) } \\
\hline & Cases $^{*}(n=231)$ & Controls* $^{*}(n=284)$ & Age OR $(95 \% \mathrm{Cl})$ & aOR $(95 \% \mathrm{Cl})$ \\
\hline$>30$ pack-years & $103(44.6)$ & $29(10.2)$ & $7.6(4.7$ to 12.4$)$ & 6.9 (3.7 to 12.8$)$ \\
\hline 10-30 pack-years & $17(7.4)$ & $19(6.7)$ & $2.3(1.1$ to 4.8$)$ & 1.9 (0.8 to 4.7$)$ \\
\hline$<10$ pack-years & $8(3.5)$ & 37 (13.0) & 0.6 (0.3 to 1.5) & 0.5 (0.2 to 1.6) \\
\hline Non-smokers & $103(44.6)$ & $199(70.1)$ & 1.0 & 1.0 \\
\hline
\end{tabular}

ORs were adjusted for age (age OR) and for age, sex, regular alcohol consumption, reported hypertension, hypercholesterolaemia, diabetes and $\mathrm{BMI}(\mathrm{aOR})$.

${ }^{*}$ Among current smokers, 18 cases and 20 controls did not specify the number of cigarettes smoked and so were left out of this analysis. aOR, adjusted OR; BMI, body mass index. 
Table 3 Risk of Ml among non-smokers and ex-smokers in relation to $(A)$ passive smoking in a home or public setting and (B) with duration of passive smoke exposure in the different settings

\section{Among non-smokers and ex-smokers only}

(A) Risk of passive smoke exposure

\begin{tabular}{|c|c|c|c|c|}
\hline & Cases* $^{*}(n=248)$ & Controls $(n=360)$ & Age OR $(95 \% \mathrm{Cl})$ & $\begin{array}{l}\text { aOR } \\
(95 \% \mathrm{Cl})\end{array}$ \\
\hline $\begin{array}{l}\text { Exposure to passive smoking } \\
\text { at home and in public }\end{array}$ & $43(17.3)$ & $37(10.3)$ & $1.9(1.1$ to 3.3$)$ & $3.2(1.7$ to 6.3$)$ \\
\hline $\begin{array}{l}\text { Exposure to passive smoking } \\
\text { only at home }\end{array}$ & $12(4.8)$ & $10(2.8)$ & 1.7 (0.7 to 4.3$)$ & $2.0(0.7$ to 5.6$)$ \\
\hline $\begin{array}{l}\text { Exposure to passive smoking } \\
\text { only in public settings }\end{array}$ & $122(49.2)$ & $202(56.1)$ & $1.0(0.7$ to 1.4$)$ & $1.2(0.7$ to 2.0$)$ \\
\hline \multicolumn{5}{|c|}{ (B) Risk with duration of passive smoke exposure } \\
\hline & Cases $(n=248)$ & Controls $(n=360)$ & $\begin{array}{l}\text { Age OR } \\
(95 \% \mathrm{Cl})\end{array}$ & $\begin{array}{l}\text { aOR } \\
(95 \% \mathrm{Cl})\end{array}$ \\
\hline \multicolumn{5}{|l|}{ Duration of home exposure } \\
\hline$<1$ hour/day & 33 (13.3) & $26(7.2)$ & $2.0(1.1-3.4)$ & $2.9(1.5$ to 5.6$)$ \\
\hline $\begin{array}{l}\text { Not exposure to passive } \\
\text { smoking at home }\end{array}$ & $193(77.8)$ & $313(86.9)$ & 1.0 & 1.0 \\
\hline \multicolumn{5}{|l|}{$\begin{array}{l}\text { Duration of passive smoking } \\
\text { in public }\end{array}$} \\
\hline$>5$ hours/day & $32(12.9)$ & $35(9.7)$ & $1.3(0.7-2.2)$ & $1.6(0.8$ to 3.1$)$ \\
\hline 1-5 hours/day & $72(29.0)$ & $95(26.4)$ & $1.2(0.8-1.8)$ & $1.6(0.9$ to 2.6$)$ \\
\hline$<1$ hour/day & $61(24.6)$ & $109(30.3)$ & $0.9(0.6-1.4)$ & $1.2(0.7$ to 2.0$)$ \\
\hline $\begin{array}{l}\text { Not exposure to passive } \\
\text { smoking in public }\end{array}$ & $83(33.5)$ & $121(33.6)$ & 1.0 & 1.0 \\
\hline
\end{tabular}

ORs were adjusted for age (age OR) and for age, sex, regular alcohol consumption, reported hypertension, hypercholesterolaemia, diabetes and $\mathrm{BMI}(\mathrm{aOR})$.

* 9 cases did not specify exposure to passive smoking in the questionnaire and so were left out of this analysis.

aOR, adjusted OR; BMI body mass index.

respectively). The risk of MI associated with exposure to passive smoke at home was elevated irrespective of duration of exposure, while the OR for passive smoking in a public setting was elevated only if exposure was greater than 1 hour per day (table 3B).

\section{The effect of active smoking on inflammation and lipid profile}

Among male controls, current smokers had higher levels of hs-CRP when compared with non-smokers (median $2.05 \mathrm{mg} / \mathrm{L}$ vs $1.28 \mathrm{mg} / \mathrm{L}$, respectively, p value $<0.05$ ), while ex-smokers had intermediate hs-CRP levels between current smokers and non-smokers (median $1.69 \mathrm{mg} / \mathrm{L}$ ). Current smokers had higher fasting triglyceride levels and total cholesterol:HDL cholesterol ratio, and lower HDL cholesterol compared with non-smokers. Ex-smokers had a lipid profile similar to that of non-smokers, with the exception of serum triglyceride levels, which were higher than those found in non-smokers $(1.29 \mathrm{mmol} / \mathrm{L}$ vs $1.07 \mathrm{mmol} / \mathrm{L}, \mathrm{p}$ value $<0.05)$ (table $4 \mathrm{~A})$.
The increased risk of MI with a higher number of packyears was reflected by higher levels of hs-CRP levels, total cholesterol, LDL cholesterol, triglycerides, non-HDL cholesterol and total cholesterol to HDL cholesterol ratio. No changes in $\mathrm{BMI}$ were evident with increasing pack-years (table 4B).

\section{Effect of passive smoking on inflammation and lipid profile}

Among male controls, levels of total cholesterol, triglycerides, total cholesterol to HDL cholesterol ratio and non-HDL cholesterol were higher in non-smokers and ex-smokers exposed to passive smoking at home and in public settings than among those not exposed to passive smoking (table 4C). These differences were observed even after excluding ex-smokers who had abstained from smoking for less than 15 years to eliminate any residual effect of past active smoking on the lipid profile (data not shown). No differences in hs-CRP levels were observed between those exposed to passive 
Table 4 Mean age and median levels and interquartile ranges of biochemical parameters and BMI in male controls by (A) smoking status, $(B)$ pack-years and $(C)$ passive smoke exposure among non-smokers and ex-smokers who have abstained from smoking for $>15$ years

\begin{tabular}{lccc}
\hline (A) Smoking status & & & \\
\hline & Smokers $(\mathbf{n = 8 0})$ & Ex-smokers (n=131) & Non-smokers (n=116) \\
\hline Age (years), mean (range) & $53(23-70)$ & $59(20-73)$ & $53(20-70)$ \\
\hline Hs-CRP (mg/L) & $2.05(0.83-4.21)^{\star}$ & $1.69(0.78-3.00)$ & $1.28(0.64-2.53)$ \\
Total cholesterol (mmol/L) & $5.38(4.80-6.05)$ & $5.48(4.71-6.13)$ & $5.25(4.69-5.83)$ \\
LDL cholesterol (mmol/L) & $3.44(2.85-4.04)$ & $3.42(2.68-4.11)$ & $3.33(2.81-3.86)$ \\
HDL cholesterol (mmol/L) & $1.20(1.08-1.42)^{\star}$ & $1.35(1.12-1.61)$ & $1.35(1.16-1.54)$ \\
\hline Triglycerides (mmol/L) & $1.46(1.06-1.88)^{\star *}$ & $1.29(0.88-1.86)^{\star}$ & $1.07(0.75-1.55)$ \\
Total cholesterol: HDL & $4.44(3.49-5.22)^{\star}$ & $3.96(3.26-4.95)$ & $3.88(3.20-4.62)$ \\
Non-HDL cholesterol (mmol/L) & $4.19(3.39-4.86)$ & $4.09(3.24-4.83)$ & $3.91(3.24-4.50)$ \\
BMl (kg/m2) & $28.4(25.0-32.0)$ & $29.1(27.2-32.2)$ & $28.1(25.8-32.2)$ \\
\hline
\end{tabular}

(B) Pack-years $†$

\begin{tabular}{|c|c|c|c|c|c|}
\hline & $>30$ pack-years $(n=24)$ & $\begin{array}{l}10-30 \text { pack-years } \\
(n=13)\end{array}$ & \multicolumn{2}{|c|}{$<10$ pack-years $(n=27)$} & Non-smokers $(n=116)$ \\
\hline Age (years), mean (range) & $59(47-70)^{*}$ & $53(34-69)$ & \multicolumn{2}{|c|}{$44(23-68)^{*}$} & $53(20-70)$ \\
\hline Total cholesterol (mmol/L) & $5.78(5.06-6.01)^{\star}$ & $5.02(4.74-6.98)$ & \multicolumn{2}{|c|}{$5.14(4.41-5.85)$} & $5.25(4.69-5.83)$ \\
\hline LDL cholesterol (mmol/L) & $3.79(3.10-3.98)^{\star}$ & $3.21(3.03-4.59)$ & \multicolumn{2}{|c|}{$3.03(2.51-3.75)$} & $3.33(2.81-3.86)$ \\
\hline Total cholesterol: HDL & $4.98(3.76-6.05)^{\star \star}$ & $4.34(3.89-5.59)^{*}$ & \multicolumn{2}{|c|}{$3.78(3.24-4.77)$} & $3.88(3.20-4.62)$ \\
\hline $\begin{array}{l}\text { Non-HDL-cholesterol } \\
(\mathrm{mmol} / \mathrm{L})\end{array}$ & $4.50(3.99-4.86)^{\star \star}$ & $3.99(3.47-5.73)$ & \multicolumn{2}{|c|}{$3.68(3.13-4.54)$} & $3.91(3.24-4.50)$ \\
\hline $\mathrm{BMI}(\mathrm{kg} / \mathrm{m} 2)$ & $27.7(24.8-31.5)$ & $30.0(25.3-36.3)$ & \multicolumn{2}{|c|}{$28.2(24.3-31.8)$} & $28.1(25.8-32.2)$ \\
\hline Age (years), mean (range) & \multicolumn{2}{|c|}{$59(43-70)$} & \multicolumn{2}{|r|}{$54(20-71)$} & \\
\hline $\mathrm{Hs}-\mathrm{CRP}(\mathrm{mg} / \mathrm{L})$ & \multicolumn{2}{|c|}{$1.20(0.69-3.02)$} & \multicolumn{2}{|r|}{$1.33(0.72-2.34)$} & \\
\hline Total cholesterol (mmol/L) & \multicolumn{2}{|c|}{$5.73(4.91-6.57)^{\star}$} & \multicolumn{3}{|c|}{$5.23(4.40-5.77)$} \\
\hline LDL cholesterol (mmol/L) & \multicolumn{2}{|c|}{$3.37(2.33-4.41)$} & \multicolumn{3}{|c|}{3.17 (2.58-3.72) } \\
\hline HDL cholesterol (mmol/L) & \multicolumn{2}{|c|}{$1.35(1.18-1.58)$} & \multicolumn{3}{|c|}{$1.45(1.22-1.69)$} \\
\hline Triglycerides (mmol/L) & \multicolumn{2}{|c|}{$1.50(0.99-2.40)^{*}$} & \multicolumn{3}{|c|}{$1.03(0.78-1.40)$} \\
\hline Total cholesterol: HDL & \multicolumn{2}{|c|}{$4.23(3.34-4.93)^{\star}$} & & $3.61(2.93-4.03)$ & \\
\hline Non-HDL-cholesterol (mmol/L) & $4.36(3.3$ & $39-5.18)^{*}$ & & $3.70(2.98-4.33)$ & \\
\hline $\mathrm{BMI}\left(\mathrm{kg} / \mathrm{m}^{2}\right)$ & $29.8(27$ & $0-32.6)$ & & $28.7(26.1-32.1)$ & \\
\hline
\end{tabular}

The $p$ values, calculated according to the two-tailed Mann-Whitney tests, compare that category with non-smokers for $(A)$ and $(B)$ and with the not exposed for (C).

${ }^{*} \mathrm{p}<0.05 ;{ }^{* *} \mathrm{p}<0.01$.

†16 male smoker controls did not specify the number of cigarettes smoked and were thus excluded from this analysis.

BMI. body mass index; HDL, high-density lipoprotein; hs-CRP, high-sensitivity C reactive protein; LDL, low-density lipoprotein.

smoking and those not exposed. Any difference in the impact of home and public passive smoke exposure on inflammation and lipid metabolism could not be investigated due to the small number of male controls exposed to passive smoking solely at home.

\section{Impact of smoking cessation on biochemical parameters and risk of MI}

The risk of MI was 2.5-fold (95\% CI 1.0 to 5.3) for those who stopped smoking 1 to 4 years earlier. Ex-smokers 
Table 5 Risk of MI with (A) increasing years from smoking cessation and $(B)$ median levels and interquartile ranges of biochemical parameters, BMI and mean age with years from smoking cessation among male controls

\begin{tabular}{|c|c|c|c|c|}
\hline \multicolumn{5}{|c|}{ (A) Risk of MI with years from smoking cessation } \\
\hline $\begin{array}{l}\text { Years from smoking } \\
\text { cessation }\end{array}$ & Casest (n=200) & Controls† $(n=356)$ & Age OR $(95 \% \mathrm{Cl})$ & aOR $(95 \% \mathrm{Cl})$ \\
\hline $1-4$ years & $22(11.0)$ & $19(5.3)$ & $2.9(1.5$ to 5.9$)$ & 2.5 (1.0 to 5.3$)$ \\
\hline $5-10$ years & $12(6.0)$ & $21(5.9)$ & $1.2(0.5$ to 2.5$)$ & $1.0(0.4$ to 2.6$)$ \\
\hline $11-15$ years & $13(6.5)$ & $25(7.0)$ & $1.0(0.5$ to 2.1$)$ & $1.0(0.4$ to 2.3$)$ \\
\hline$>15$ years & $50(25.0)$ & $92(25.8)$ & $0.9(0.6$ to 1.3$)$ & $0.8(0.5$ to 1.3$)$ \\
\hline
\end{tabular}

(b) Years from smoking cessation

\begin{tabular}{|c|c|c|c|c|c|}
\hline & $1-4$ years $(n=14)$ & $5-10$ years $(n=15)$ & $10-15$ years $(n=21)$ & $>15$ years $(n=75)$ & $\begin{array}{l}\text { Non-smokers } \\
(n=116)\end{array}$ \\
\hline Age (years), mean (range) & $54(26-68)$ & $57(28-70)$ & $58(32-70)^{\star}$ & $62(40-73)^{\star}$ & $53(20-70)$ \\
\hline Hs-CRP (mg/L) & $1.77(1.44-4.54)$ & $1.56(0.72-2.81)$ & $2.19(0.76-4.30)$ & $1.68(0.78-2.74)$ & $1.28(0.64-2.53)$ \\
\hline Total cholesterol (mmol/L) & $5.37(4.43-6.28)$ & $5.78(5.07-6.37)$ & $5.97(5.26-6.32)^{\star}$ & $5.41(4.55-5.94)$ & $5.25(4.69-5.83)$ \\
\hline LDL-cholesterol (mmol/L) & $3.41(2.42-4.20)$ & $3.79(2.91-4.04)$ & $3.75(3.12-4.24)$ & $3.22(2.55-4.09)$ & $3.33(2.81-3.86)$ \\
\hline Total cholesterol: HDL & $4.16(3.42-4.79)$ & $3.96(3.06-5.50)$ & $3.75(3.12-4.24)$ & $3.87(3.11-4.70)$ & $3.88(3.20-4.62)$ \\
\hline Non-HDL-chol (mmol/L) & 3.88 (3.28-4.95) & 4.40 (3.18-5.28) & $4.43(3.95-5.05)^{\star}$ & $3.86(3.07-4.81)$ & $3.91(3.24-4.50)$ \\
\hline $\mathrm{BMI}(\mathrm{kg} / \mathrm{m} 2)$ & $30.1(28.1-35.1)^{*}$ & $30.5(27.8-37.2)^{\star \star}$ & $28.7(26.8-31.2)$ & $28.7(26.6-31.6)$ & $28.1(25.8-32.2)$ \\
\hline
\end{tabular}

Levels among non-smokers are also presented.

ORs were adjusted for age (age OR) and for age, sex, regular alcohol consumption, reported hypertension, hypercholesterolaemia, diabetes and BMI (AdjOR).

${ }^{*} p<0.05 ;{ }^{* *} p<0.01$.

†Ex-smoker cases and controls who stopped smoking less than a year ago were not included in this analysis. The $p$ values, calculated according to the two-tailed Mann-Whitney tests, compare that category with non-smokers.

aOR, adjusted OR' BMI, body mass index; MI myocardial infarction.

having abstained from smoking for 5 years or more showed no increased risk of MI (table 5A). Further adjustment for passive smoke exposure along with the conventional risk factors of MI did not materially change the ORs. No considerable differences were observed in hs-CRP levels with increasing years of smoking cessation.

Serum triglyceride levels decreased with years from smoking cessation, with male controls who had stopped smoking more than 15 years previously having similar levels as non-smokers (table 5B).

\section{DISCUSSION}

Both active and passive smoking are risk factors for MI. The risk of MI drastically increases with smoking intensity and decreases after 5 years from smoking cessation. The increased risk of MI associated with smoking was reflected by a higher inflammatory state (as indicated by hs-CRP levels) and altered lipid profile, with elevation of triglyceride levels and decreased HDL cholesterol levels being the most pronounced changes.

Passive smoking emerged as a strong risk factor for MI (aOR 3.2 (95\% CI 1.7 to 6.3)). In this study, passive smoke exposure was associated with higher levels of triglycerides, total cholesterol: HDL-cholesterol ratio and
non-HDL-cholesterol, which may be mediating at least part of the risk of MI associated with passive smoking. Though there are few studies on the effects of passive smoking on the lipid profile, our results are concordant with those from two other studies, ${ }^{13} 14$ thus strengthening the evidence of a true effect.

The effect of passive smoking was strong in a home setting. A high risk of acute MI has been previously observed among individuals who lived with a smoking spouse or had children who smoked. ${ }^{6}$ Although it has been suggested that drinking often accompanied passive smoke exposure in public settings, ${ }^{15}$ the difference between the risks in the two settings analysed was not due to the effect of alcohol consumption in a public setting, as the risk of MI due to public passive smoke exposure was low in both alcohol drinkers and non-alcohol drinkers.

We cannot exclude under-reporting of active smoking. This would lead to misclassification of active smokers as non-smokers. In addition, despite clearly specifying during the interview that exposure to passive smoking in public was only valid if it occurred in a closed environment, it could not be excluded that individuals also reported exposure to passive smoking that occurred in open public spaces. Individuals who reported to have 
been exposed to public passive smoking may have been exposed years ago and the deleterious effect may have subsided. These limitations might explain the observed discrepancy in the risk of MI associated with passive smoke exposure between a home and public setting. If smokers are more likely to live with a smoker, under-reporting of active smoking could result in an excessive misclassification of active smokers as passive smokers resulting in a higher risk for passive smoking at home. Furthermore, recall bias might have occurred, since cases with MI might be less likely to report that they smoke when compared with controls. In that case, the actual risk of MI for active smokers might even have been higher.

Conflicting literature still exists on the dose-response relation between passive smoke exposure and risk of MI. ${ }^{16}{ }^{17}$ In this study, the strong risk of MI due to passive smoke exposure at home was independent of the duration of exposure and already had an effect with very short exposure time. While passive smoke exposure in a public setting for a short duration did not increase the risk of MI, elevated aORs were observed among individuals exposed for a longer duration.

Observations on both the risk of MI due to active smoking and effects of smoking on inflammation and lipid profile are similar to previous findings, where the increased predisposition for MI among smokers has been associated with an abnormal lipid profile. ${ }^{18} 19$

Concordant with our findings, the dose-response increase in risk of MI with pack-years was reported in the INTERHEART Study where a strong and graded relation was found between the number of cigarettes smoked and risk of MI. ${ }^{20}$ This risk was reflected by an increase in markers of inflammation. ${ }^{21}$ A higher number of pack-years was associated with elevated levels of total cholesterol, triglycerides and LDL cholesterol and a simultaneous reduction in HDL cholesterol levels. Such observations confirm findings of other authors who reported a direct relationship between increasing packyears and abnormal lipid profiles. ${ }^{22} 23$

Smoking cessation was associated with a decreased risk of MI. The risk of MI due to past smoking was no longer evident 5 years after smoking cessation. Other authors reported similar beneficial effect of smoking cessation, including reduced risk of MI, stroke, cardiovascular disease and total mortality. ${ }^{24-27}$ However, conflicting literature still exits about the impact of smoking cessation on the lipid profile. ${ }^{910}$ In the current study, at least part of the benefit of smoking cessation was attributed to improved lipid profile. Triglyceride levels decreased with increasing years from smoking cessation, with ex-smokers who have abstained from smoking for more than 15 years having similar levels as non-smokers.

In conclusion, both active and passive smoking conveyed an equally deleterious effect on the risk of MI. A dose-response increase in risk was observed with increasing pack-years. At least part of the risk of MI due to active smoking was mediated through a higher inflammatory state, while both active and passive smoking were associated with an altered lipid profile. Programmes to increase awareness on the risk of MI posed by passive smoking should be set up. Laws banning smoking in public, including workplaces, should be established in countries where smoking is still allowed in public spaces and enforced in countries where legislation isalready in place. Smoking cessation should be encouraged, as at least some of the pathological effects of smoking are reversible. Given the high prevalence of both active and passive smoking and their strong effect on the risk of MI, both should be considered when studying the effect of other lifestyle, environmental and genetic factors.

Acknowledgements The following departments at Mater Dei Hospital, Msida, Malta are also acknowledged: the Departments of Cardiology and Medicine were involved in recruitment of cases, the ECG department for conducting ECGs on all research subjects, and Department of Pathology for phlebotomy, biochemical and hematological testing. The Laboratory of Molecular Genetics carried out isoelectric focusing of haemoglobins. The CCU ward, outpatients, ECG department and laboratory at Gozo General Hospital, Victoria, Gozo were involved in the recruitment of Gozitan research subjects. Mr. Adrian Pleven and Ms. Anna Lisa Sciortino are acknowledged for overseeing biochemical tests carried out on the Immulite 2000.

Contributors All authors reviewed and provided edits and comments on manuscript drafts. In addition, authors had the following responsibilities: SBW designed the MAMI Study and was the principal investigator; RA was involved in research subject recruitment, laboratory testing, sample processing and all data analyses and was responsible for writing this manuscript; PD was involved in research subject recruitment, clinically assessed all cases to verify they fit in the recruitment criteria, and was responsible for waist and hip measurements; CD was responsible for overall study design and for overseeing data analysis; KC was responsible for ethical issues, clinical aspects, and logistics in recruitment; RF was involved in recruitment, selection of testing methodology, running of the project, and scientific advice. SBW had full access to all the data, oversaw all phases of the study and takes responsibility for the integrity of the data, accuracy of the data analysis and contents of this article.

Funding This work was carried out as part of the MAMI Study, a collaboration between the University of Malta and the Malta Department of Health. It was supported by national funding through the R\&I program 2008 administered by the Malta Council for Science and Technology (MCST). The research work disclosed in this publication was also partially funded by the Malta Government Scholarships Scheme (MGSS). Open access publication fees were funded by Train MALTA, a European Union's Horizon 2020 research and innovation program under grant agreement No. 692041

Competing interests None declared.

Ethics approval Research Ethics Committee, University of Malta.

Provenance and peer review Not commissioned; externally peer reviewed.

Open Access This is an Open Access article distributed in accordance with the Creative Commons Attribution Non Commercial (CC BY-NC 4.0) license, which permits others to distribute, remix, adapt, build upon this work non-commercially, and license their derivative works on different terms, provided the original work is properly cited and the use is non-commercial. See: http://creativecommons.org/ licenses/by-nc/4.0/

(C) Article author(s) (or their employer(s) unless otherwise stated in the text of the article) 2017. All rights reserved. No commercial use is permitted unless otherwise expressly granted.

\section{REFERENCES}

1. Burns DM. Epidemiology of smoking-induced cardiovascular disease. Prog Cardiovasc Dis 2003;46:11-29.

2. Michael Pittilo R. Cigarette smoking, endothelial injury and cardiovascular disease. Int J Exp Pathol 2000;81:219-30.

3. Gossett LK, Johnson HM, Piper ME, et al. Smoking intensity and lipoprotein abnormalities in active smokers. J Clin Lipidol 2009;3:372-8.

4. Kannel WB, D'Agostino RB, Belanger AJ. Fibrinogen, cigarette smoking, and risk of cardiovascular disease: insights from the Framingham Study. Am Heart J 1987;113:1006-10. 
5. Napoli C, Ignarro LJ. Nitric oxide and atherosclerosis. Nitric Oxide 2001;5:88-97.

6. Ciruzzi M, Pramparo P, Esteban O, et al. Case-Control Study of Passive Smoking at Home and risk of acute myocardial infarction. $J$ Am Coll Cardiol 1998;31:797-803.

7. Iversen B, Jacobsen BK, Løchen ML. Active and passive smoking and the risk of myocardial infarction in 24,968 men and women during 11 year of follow-up: the Troms $\varnothing$ Study. Eur J Epidemiol 2013;28:659-67.

8. Panagiotakos DB, Chrysohoou C, Pitsavos C, et al. The association between secondhand smoke and the risk of developing acute coronary syndromes, among non-smokers, under the presence of several cardiovascular risk factors: the CARDIO2000 case-control study. BMC Public Health 2002;2:9.

9. Maeda K, Noguchi Y, Fukui T. The effects of cessation from cigarette smoking on the lipid and lipoprotein profiles: a meta-analysis. Prev Med 2003;37:283-90.

10. Gepner AD, Piper ME, Johnson HM, et al. Effects of smoking and smoking cessation on lipids and lipoproteins: outcomes from a randomized clinical trial. Am Heart J 2011;161:145-51.

11. Alpert JS, Thygesen K, Antman E, et al. Myocardial infarction redefined--a consensus document of The Joint European Society of Cardiology/American College of Cardiology Committee for the redefinition of myocardial infarction. J Am Coll Cardiol 2000;36:959-69.

12. World Health Organization (WHO) Document Production Services, Geneva, Switzerland. Waist circumference and waist-hip ratio: report of a WHO expert consultation. Geneva. (8-11th Dec 2008).

13. Feldman J, Shenker IR, Etzel RA, et al. Passive smoking alters lipid profiles in adolescents. Pediatrics 1991;88:259-64.

14. Holay MP, Paunikar NP, Joshi PP, et al. Effect of passive smoking on endothelial function in healthy adults. $J$ the Assoc of Physicians of India 2004;52:114-7.

15. Harrison EL, Desai RA, McKee SA. Nondaily smoking and alcohol use, hazardous drinking, and alcohol diagnoses among young adults: findings from the NESARC. Alcohol Clin Exp Res 2008;32:2081-7.
16. He J, Vupputuri S, Allen $\mathrm{K}$, et al. Passive smoking and the risk of coronary heart disease--a meta-analysis of epidemiologic studies. $N$ Engl J Med 1999;340:920-6.

17. Kawachi I, Colditz GA, Speizer FE, et al. A prospective study of passive smoking and coronary heart disease. Circulation 1997;95:2374-9.

18. Cauazos M. Waht is the relationship between smoking and cholesterol? 2010. Adapted from www.livestron.com (15 Feb 2017)

19. van der Vaart $H$, Postma DS, Timens W, et al. Acute effects of cigarette smoke on inflammation and oxidative stress: a review. Thorax 2004;59:713-21.

20. Yusuf S, Hawken S, Ounpuu S, et al. Effect of potentially modifiable risk factors associated with myocardial infarction in 52 countries (the INTERHEART study): case-control study. Lancet 2004;364:937-52.

21. McEvoy JW, Nasir K, DeFilippis AP, et al. Relationship of cigarette smoking with inflammation and subclinical vascular disease: the Multi-Ethnic Study of Atherosclerosis. Arterioscler Thromb Vasc Biol 2015;35:1002-10.

22. Meenakshisundaram R, Rajendiran C Thirumalaikolundusubramanian P. Lipid and lipoprotein profiles among middle aged male smokers: a study from southern India. Tob Induc Dis 2010;8:11.

23. Batta A. Smoking disrupts lipid profile. International Journal of Innovative Research and Development 2014;3:43-8.

24. Kawachi I, Colditz GA, Stampfer MJ, et al. Smoking cessation in relation to total mortality rates in women. A prospective cohort study. Ann Intern Med 1993;119:992-1000.

25. Kawachi I, Colditz GA, Stampfer MJ, et al. Smoking cessation and time course of decreased risks of coronary heart disease in middleaged women. Arch Intern Med 1994;154:169-75.

26. Critchley JA, Capewell S. Mortality risk reduction associated with smoking cessation in patients with coronary heart disease: a systematic review. JAMA 2003;290:86-97.

27. Serrano M, Madoz E, Ezpeleta I, et al. Smoking cessation and risk of myocardial reinfarction in coronary patients: a nested case-control study. Rev Esp Cardiol 2003;56:445-51. 